07,14

\title{
Разрушение АБС-пластика в стеклообразном состоянии при динамическом нагружении
}

\author{
(C) С.А. Атрошенко ${ }^{1,2}$, А.А. Чеврычкина ${ }^{1,2, \uparrow}$, А.Д. Евстифееев ${ }^{1}$, Г.А. Волков ${ }^{1,2}$ \\ ${ }^{1}$ Институт проблем машиноведения РАН, \\ Санкт-Петербург, Россия \\ ${ }^{2}$ Санкт-Петербургский государственный университет, \\ Санкт-Петербург, Россия \\ ฯ E-mail: Anastasiia.Che@gmail.com
}

Поступила в Редакцию 24 января 2019 г.

В окончательной редакции 24 января 2019 г.

Принята к публикации 6 июня 2019 г.

Статья посвящена экспериментальному и теоретическому исследованию механизмов разрушения АБСпластика в интервале скоростей деформации $10^{-4}-10^{3} 1 / \mathrm{s}$ при разной температуре испытаний (от комнатной температуры -23 до $100^{\circ} \mathrm{C}$ ). Анализируется смена вида разрушения в зависимости от скорости деформации и температуры. На основе структурно временного подхода предложена модель температурно-скоростной суперпозиции.

Ключевые слова: АБС-пластик, динамическое нагружение, стеклообразное состояние, критерий прочности, фрактографический анализ.

DOI: 10.21883/FTT.2019.11.48414.364

\section{1. Введение}

Полимеры являются основой класса конструкционных материалов, наряду с металлами и керамикой, на их основе производят новые материалы. К примеру, ударопрочный АБС-пластик (акрилонитрилбутадиенстирол) широко используется в аддитивном производстве благодаря своей температуре стеклования, достаточно высокой для формирования и сохранения формы и достаточно безопасной для экструзии. В последнее время уделяется все больше внимания к 3D-печати, как к производству конструкционного материала. Распространение применения 3D-печати требует исследования свойств аддитивного материала в различных температурно-скоростных условиях нагружения. Для АБС-пластика, как для конструкционного материала, наиболее важно изучение прочностных свойств при температурах ниже температуры стеклования.

Для многих твердых тел выполняется принцип температурно-скоростной суперпозиции прочности материала, то есть повышение температуры влияет на поведение материала также как понижение скорости деформирования. Исследование температурно-скоростной суперпозиции проводится во многих работах [1-8].

Состояние полимера в зависимости от температуры может быть стеклообразным, высокоэластичным или вязкотекучим. В каждом из состояний подтверждается принцип температурно-скоростной суперпозиции. Исследование температурно-скоростной зависимости обычно проводится отдельно для каждого состояния полимера, например, в работе [1-3] изложено исследование прочности полимера в области температур выше температуры стеклования, в работах [4-6] показана зависимость прочности от температуры и скорости нагружения в области температур ниже температуры стеклования.
В настоящей статье приводятся результаты экспериментального исследования прочности АБС-пластика в стеклообразном состоянии в диапазоне температур от 23 до $100^{\circ} \mathrm{C}$ и в диапазоне скоростей деформации $10^{-4}-10^{3} 1 / \mathrm{s}$. Статья посвящена фрактографическому исследованию АБС-пластика и согласованию полученных экспериментальных данных по температурно-скоростной зависимости прочности с позиций структурно-временного подхода $[9,10]$.

\section{2. Материал и методика исследований}

Испытания по определению прочностных свойств АБС-пластика проводились на башенном копре Instron Ceast 9350 с ускорителем на стандартных образцах ISO 8256, полученных методом аддитивной печати. Методика испытаний приведена в работе [11]. Микроструктурные исследования поверхности разрушения после ударных испытаний выполнялись с использованием микроскопа Axio Observer Z1-M в темном поле.

Полученные результаты позволили выявить скоростную зависимость прочности при увеличении скорости деформации, см. рис. 1, при температурах 23, 50, $100^{\circ} \mathrm{C}$. Также с ростом температуры было отмечено температурное разупрочнение, а именно с увеличением температуры предельное значение прочности падает.

\section{3. Расчет температурно-скоростной зависимости с позиции структурно-временного подхода}

Как уже было отмечено ранее, с ростом скорости деформации был выявлен эффект повышения предельных 


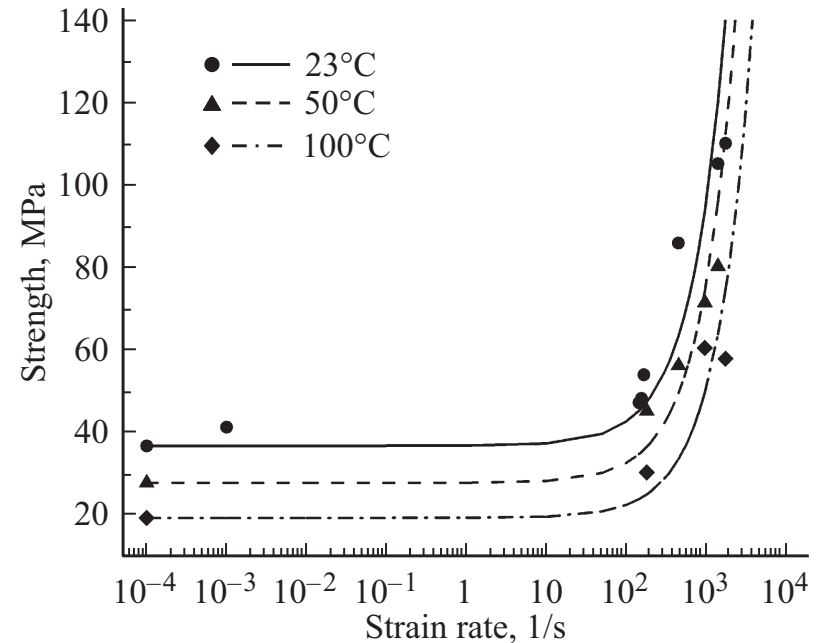

Рис. 1. Зависимость прочности от скорости деформации для разных температур. Точки соответствуют экспериментальным данным, линии - расчетным. Кривые построены по критерию (2)-(4) и значению параметров из таблицы.

значений прочности, с увеличением температуры наблюдается снижение предельных значений. Скоростная зависимость прочности хорошо описывается с позиции структурно временного подхода, где в качестве критерия разрушения выступает критерий инкубационного времени [9,10]. В основе критерия лежат принципы структурной макромеханики разрушения и понятия инкубационного времени разрушения.

В случае разрушения критерий инкубационного времени имеет вид

$$
\frac{1}{\tau} \int_{t-\tau}^{t} \frac{\sigma(s)}{\sigma_{c}} d s \leq 1
$$

где $\sigma(s)$ - приложенное растягивающее напряжение, линейно возрастающее со временем, $\sigma_{c}$ - статическая прочность разрушения, зависящая от температуры, $\tau-$ инкубационное время разрушения, зависящее от температуры, которое может служить мерой динамической прочности. Влияние температуры учитывается в следующих температурных зависимостях

$$
\begin{gathered}
\sigma_{c}(T)=\sigma_{0} \exp \left(-a \frac{T-T_{g}}{T_{g}}\right), \\
\tau(T)=\tau_{0} \exp \left(-\frac{U}{k T}\right),
\end{gathered}
$$

где $T$ - температура, $k$ - постоянная Больцмана, $T_{g}-$ температура стеклования, $\sigma_{0}, \tau_{0}, a, U-$ постоянные материала.

Параметры критерия (2)-(4) для АБС-пластика

\begin{tabular}{c|c|c|c|c}
\hline$\sigma_{0}, \mathrm{MPa}$ & $E \tau_{0}, \mathrm{MPa} \cdot \mathrm{s}$ & $U / k, \mathrm{~K}$ & $a$ & $T_{g}, \mathrm{~K}$ \\
\hline 16.7 & 15671.4 & 543.7 & 3.1 & 383
\end{tabular}

В работах $[8,9]$ показано, что критерий (1) с температурными зависимостями (2), (3) применим для металлов в широком диапазоне изменения температуры и скорости деформации.

На рис. 1 приведены результаты экспериментов и расчетные кривые для АБС-пластика в квазистатическом и динамическом режимах при температурах $23,50,100^{\circ} \mathrm{C}$, кривые соответствуют расчетам по формулам (1)-(3) с параметрами, приведенными в таблице. Представленные данные демонстрируют зависимость, которая довольно хорошо описывается критерием разрушения (1). Применимость критерия (1) для металлов и полимеров ниже температуры стеклования с одинаковыми зависимостями статической прочности (2) и инкубационного времени разрушения (3) можно объяснить тем, что механизм разрушения в обоих случаях одинаков - за счет образования микротрещин.

На основе принципа температурно-скоростной суперпозиции можно рассчитать зависимость механических свойств от скорости деформации в широком диапазоне температур. С использованием предложенного подхода можно получить данные о поведении материала в широком диапазоне изменения параметров внешнего воздействия при наличии экспериментальных данных лишь в относительно узком диапазоне. В работе наглядно продемонстрирован принцип эквивалентного действия при изменении скорости деформации и температуры. Полученные прочностные зависимости при вариации скорости приложения нагрузки и температур рассчитаны в рамках одного подхода в соответствии с моделью принципа температурно-скоростного соответствия.

Принцип температурно-скоростной суперпозиции неоднократно подвергался проверке при исследовании поведения многих полимеров, и во многих случаях он хорошо подтверждается. К числу этих исследований относится работа [3], где рассматривается метод ВильямаЛэндела-Ферри (ВЛФ), который строит теоретическую

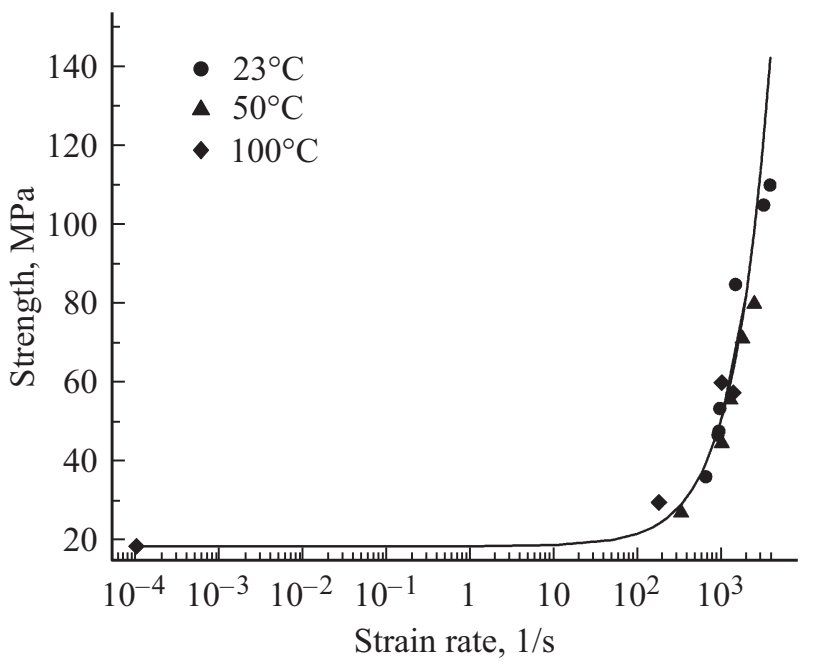

Рис. 2. Единая обобщенная кривая для температуры $100^{\circ} \mathrm{C}$ c приведенными экспериментальными данными. 

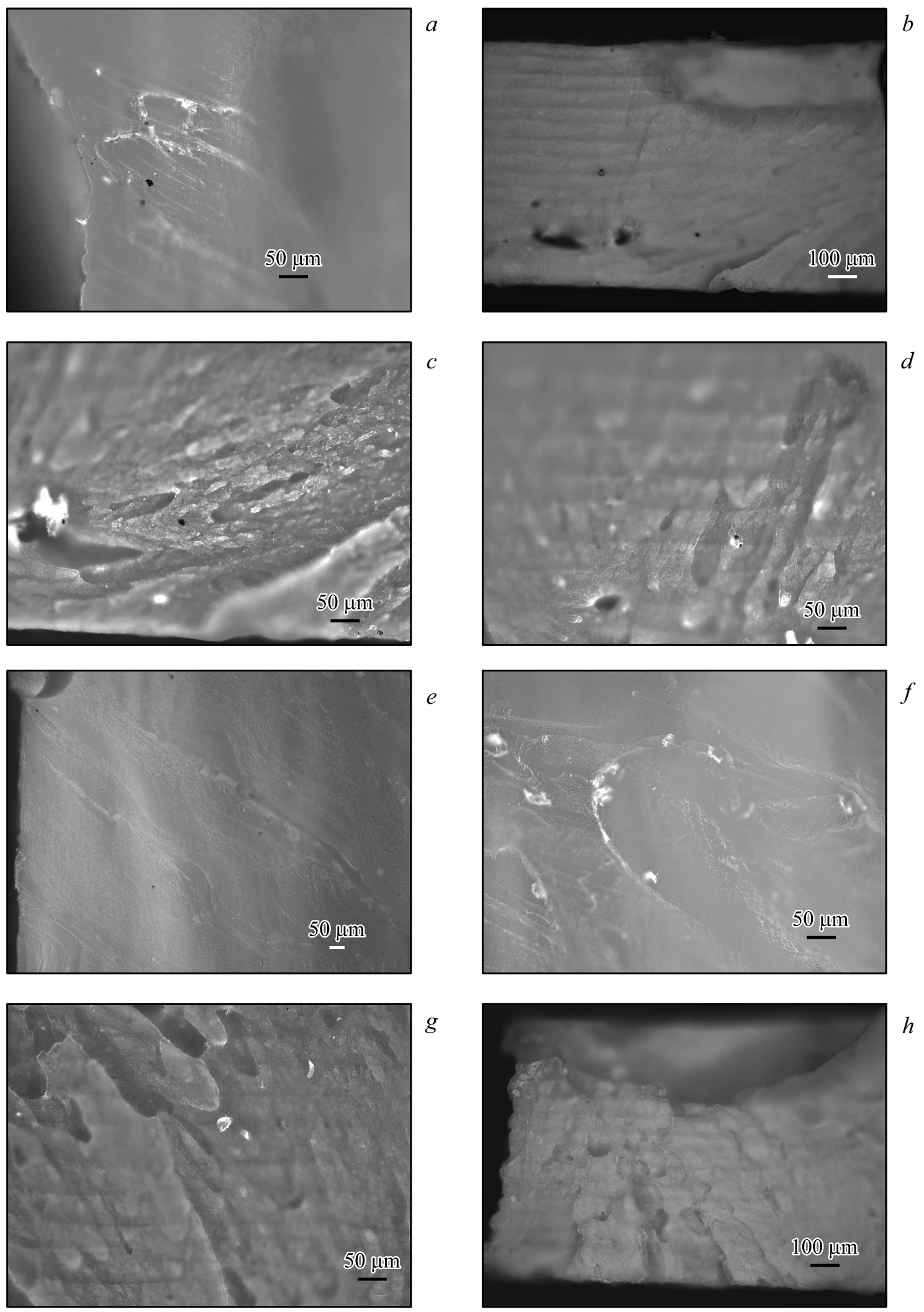

Рис. 3. Поверхность разрушения АБС-пластика, испытанного при комнатной температуре при скорости деформации $1801 / \mathrm{s}(a-d)$, при скорости деформации $4561 / \mathrm{s}(e-h)$ в темном поле. Увеличение рисунков $a, c, d, e, f, g(200$ к 1$)$; увеличение рисунков $b, h$ (100 к 1). 

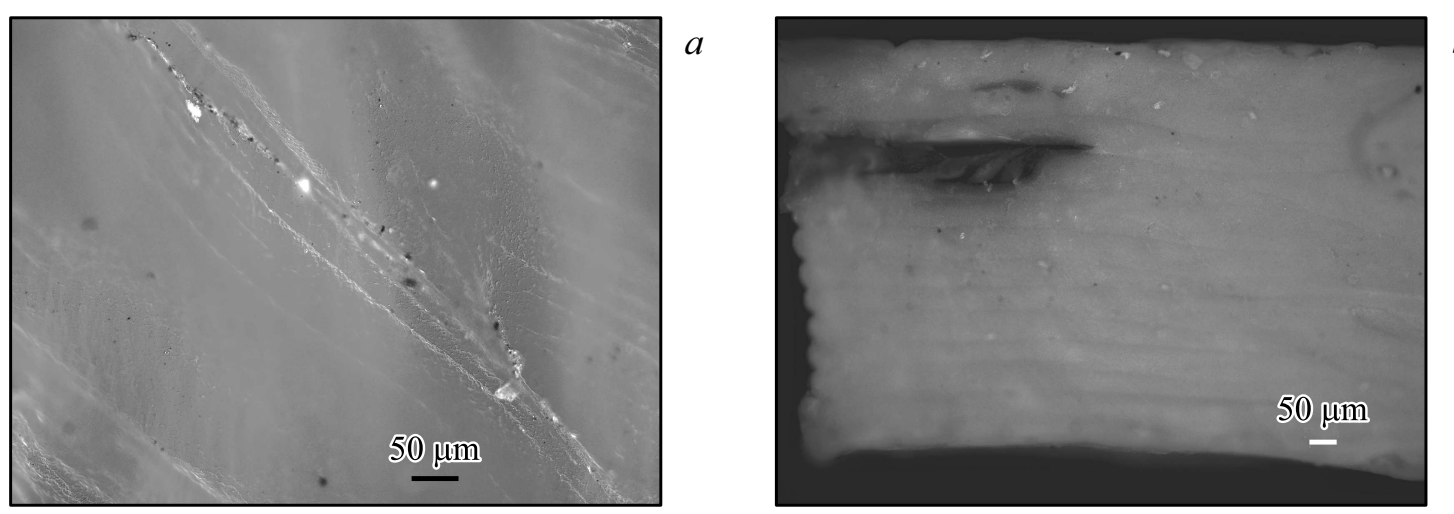

$b$
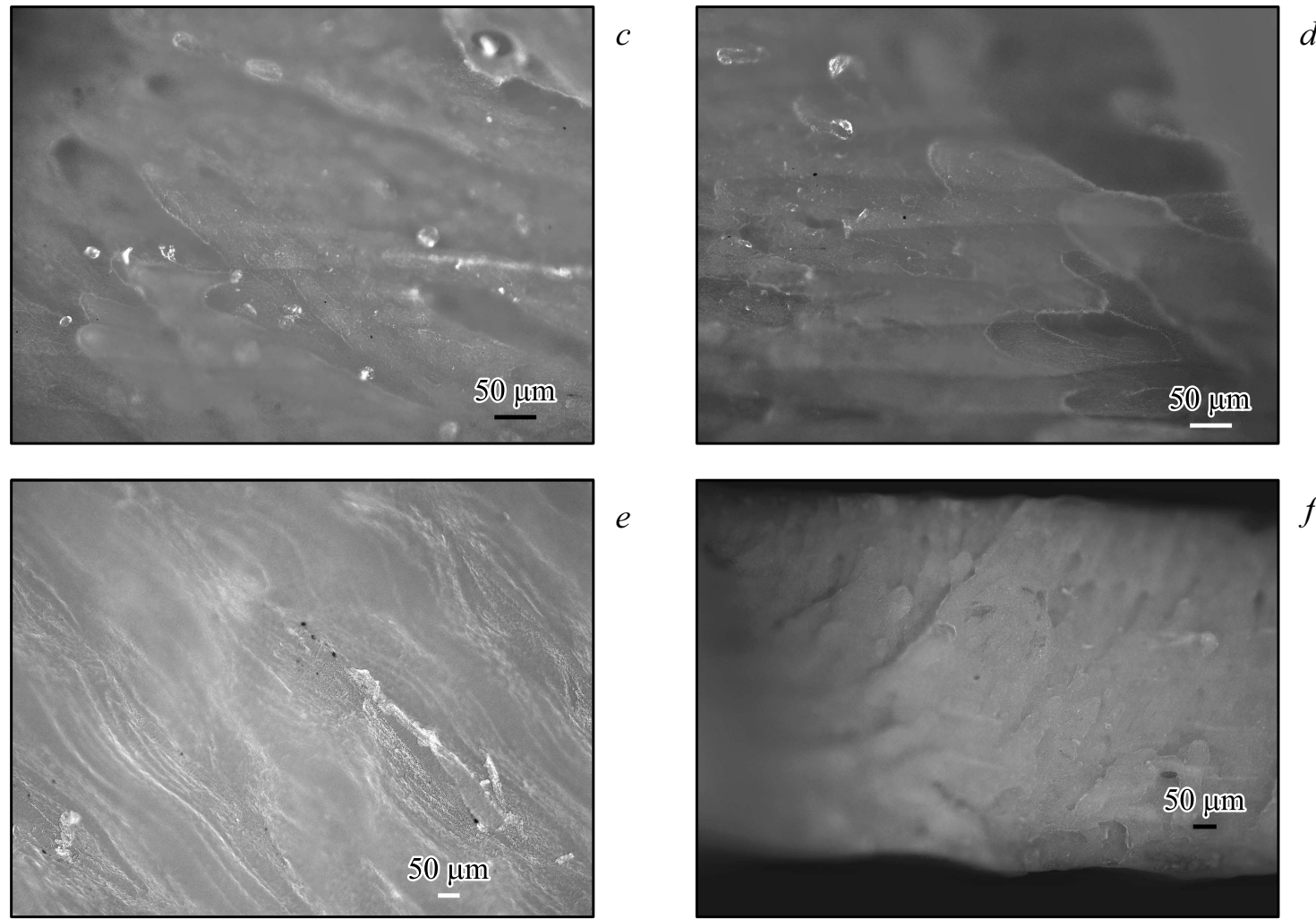

$e$
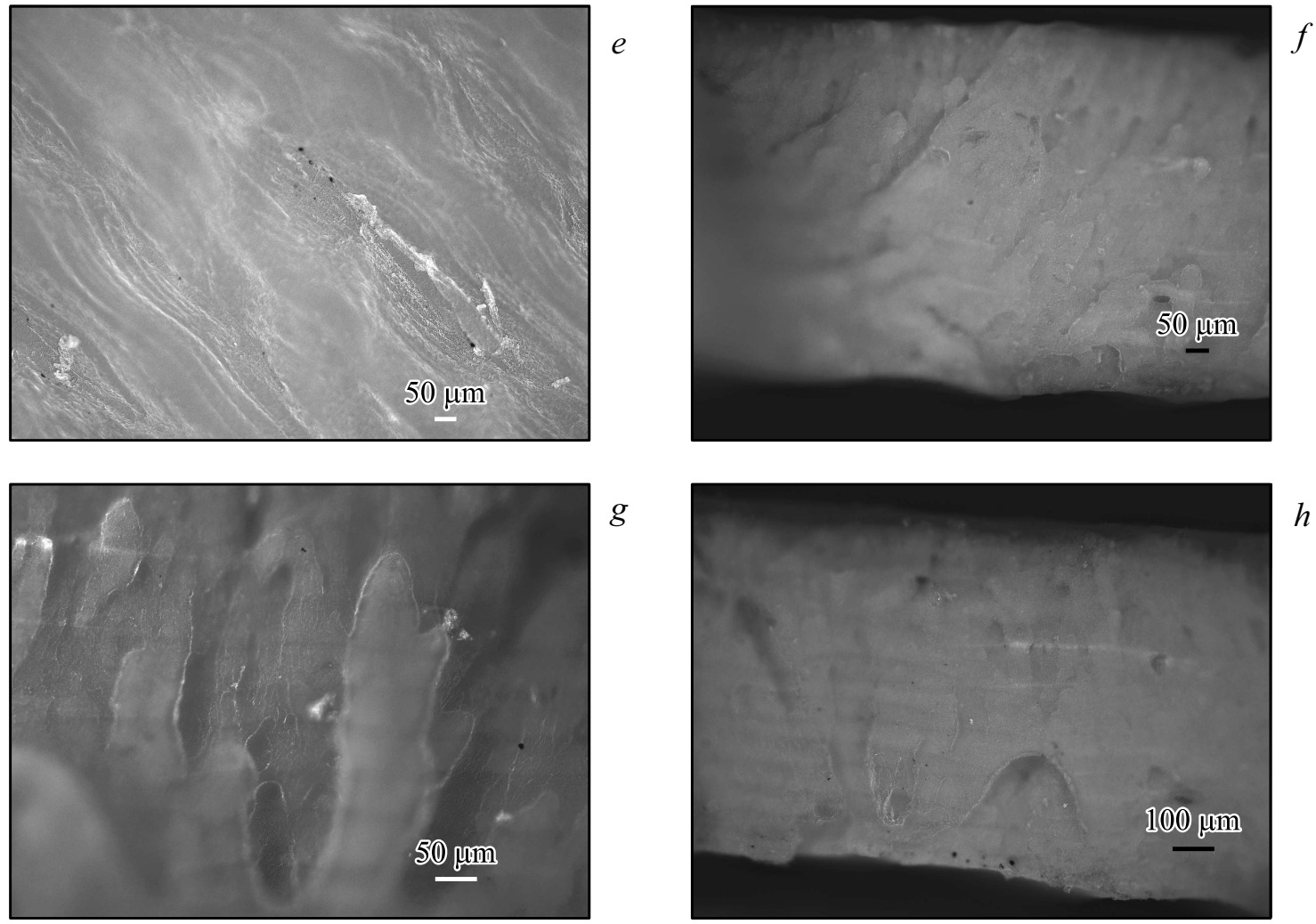

$g$

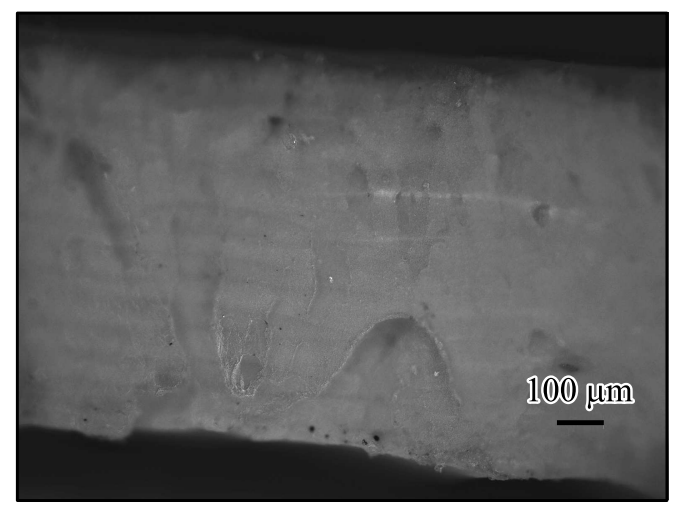

Рис. 4. Поверхность разрушения АБС-пластика, испытанного при температуре $50^{\circ} \mathrm{C}$ при скорости деформации $4561 / \mathrm{s}(a-d)$, при скорости деформации $9871 / \mathrm{s}(e-h)$ в темном поле. Увеличение рисунков $a, b, c, d, e, f, g(200$ к 1$)$; увеличение рисунка $h(100$ к 1$)$. 

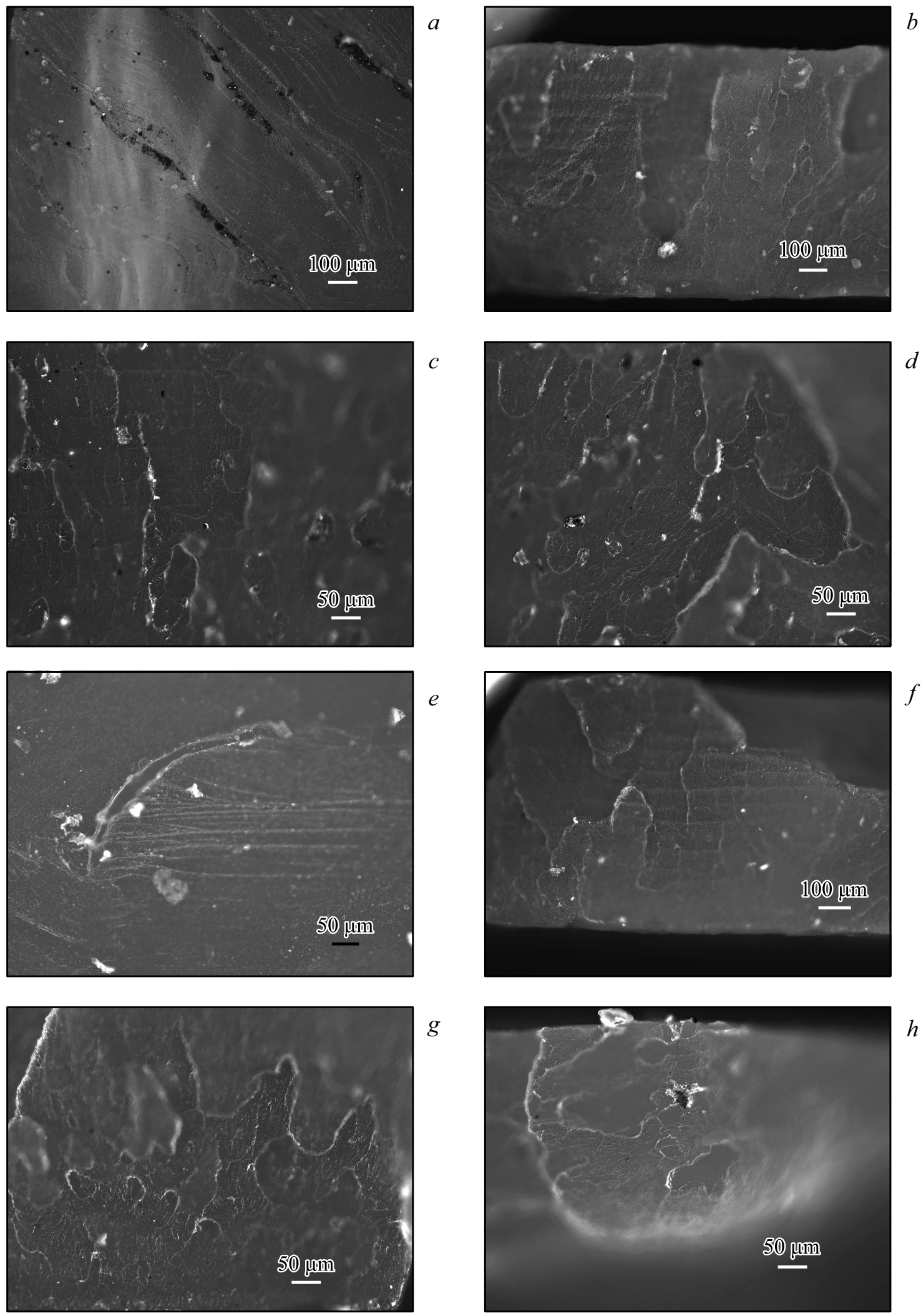

Рис. 5. Поверхность разрушения АБС-пластика, испытанного при температуре $100^{\circ} \mathrm{C}$ при скорости деформации $1801 / \mathrm{s}(a-d)$, при скорости деформации $9781 / \mathrm{s}(e-h)$, при скорости деформации $17451 / \mathrm{s}(i-l)$ в темном поле. Увеличение рисунков $c, d, e, g, h, i, j, k$ (200 к 1); увеличение рисунков $a, b, f, l(100$ к 1). 

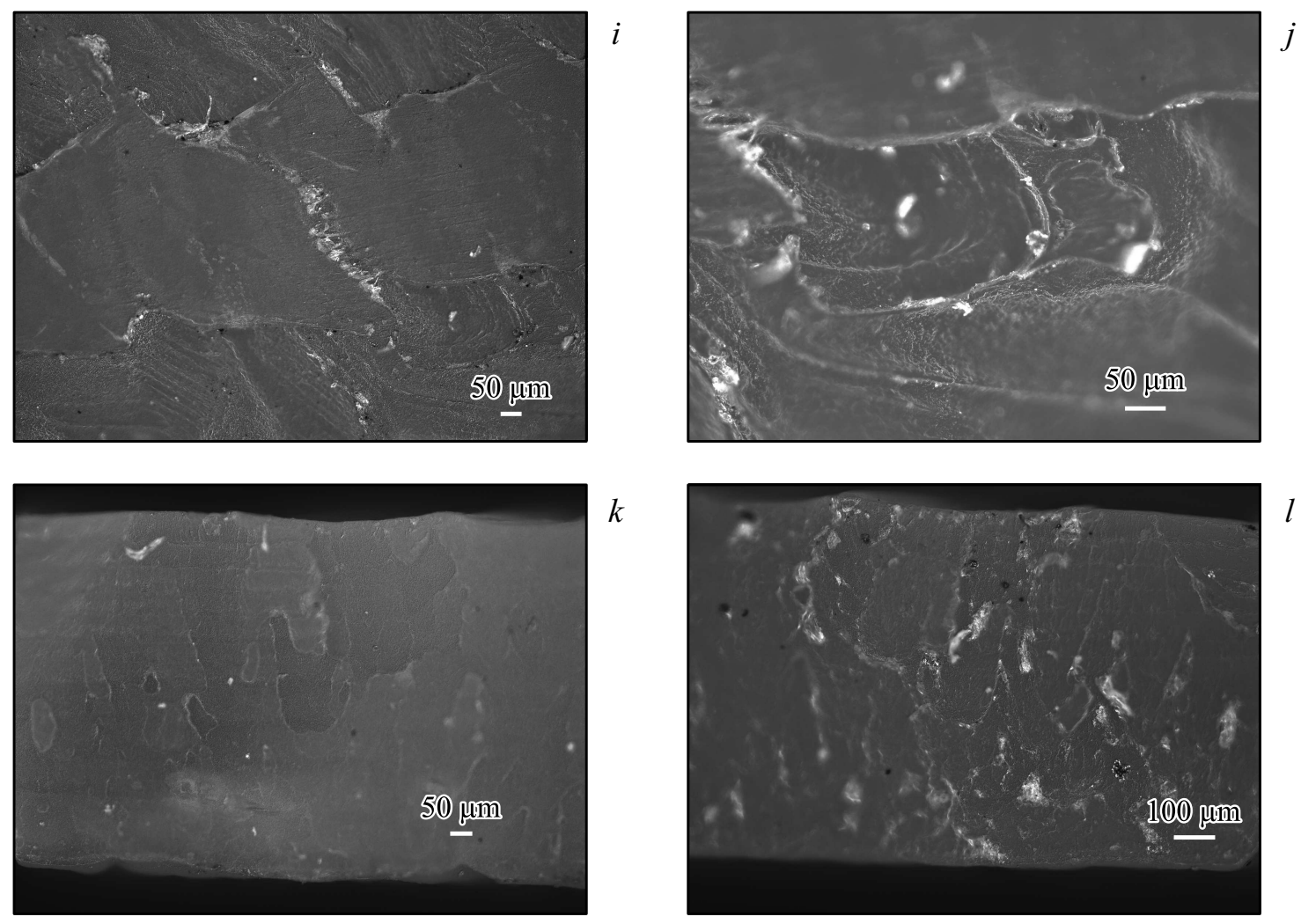

Рис. 5 (продолжение).

кривую с помощью температурного коэффициента релаксации (отношение времен релаксации при двух температурах). Метод ВЛФ работает только выше температуры стеклования, ниже температуры стеклования зависимость прочностных свойств от скорости деформации и температуры обычно строится на основе теории вязкого течения Эйринга [4-6].

Применение критерия инкубационного времени позволяет описывать поведение материала и построить единую теоретическую кривую температур для температур ниже температуры стеклования. Значение прочности $\sigma_{i}$ при температуре $T_{i}$ и скорости деформации $\dot{\varepsilon}_{i}$ соответствует значению прочности $\sigma_{i}$ при температуре $T_{j}$ и новой соответствующей скорости деформации $\dot{\varepsilon}_{n e w}$, вычисленной по простой формуле (4). В качестве температуры отсчета удобно выбрать температуру чуть ниже температуры стеклования по аналогии с методом ВЛФ, для которого советуют выбрать температуру отсчета чуть выше температуры стеклования

$$
\dot{\varepsilon}_{n e w}=2 \frac{\sigma_{i}-\sigma_{c}\left(T_{j}\right)}{E \tau\left(T_{j}\right)} .
$$

На рис. 2 приведена единая обобщенная кривая для температуры $100^{\circ} \mathrm{C}$, построенная на основе критерия (1)-(3) и значениях параметров из таблицы. Экспериментальные данные для температур $23,50^{\circ} \mathrm{C}$ отнесены к температуре $100^{\circ} \mathrm{C}$ с помощью формулы (4). Структурно временной подход позволяет построить еди- ную теоретическую кривую, не используя теорию вязкого течения Эйринга.

\section{4. Характер разрушения}

АБС-пластик - термопластичный аморфный тройной сополимер трех мономеров - акрилонитрила, бутадиена и стирола и представляет собой двухфазную систему. Статистический сополимер стирола и акрилонитрила с молекулярной массой 120-180 тысяч образует непрерывную фазу - жесткую матрицу, в которой распределены частицы бутадиенстирольного каучука размером 0.5-2 $2 \mathrm{~m}$, образующие дисперсную фазу. Доля дисперсной фазы составляет от 15 до 30\% от общей массы пластика.

Структура АБС-пластика при комнатной температуре $\left(23^{\circ} \mathrm{C}\right)$ после испытаний с различными параметрами представлена на рис. 3. При температуре $23^{\circ} \mathrm{C}$ после испытаний наблюдается слоистость материала при всех скоростях нагружения (рис. $3, b, d, g, h$ ).

Трещины располагаются вдоль слоев при меньшей скорости деформации $(1801 / \mathrm{s})$ (рис. 3,b) и поперек слоев, пересекая их, при скорости деформации 4561/s. (рис. $3, g$ ). Трещина зарождается и распространяется вдоль мест скопления включений второй фазы - бутадиенстирольного каучука при всех скоростях деформации. Параболическая область $[12,13]$ менее ярко выражена при менышей скорости деформации (рис. 3,a), а 
область повышенной шероховатости - наоборот, более развита в образце, испытанном со скоростью $1801 / \mathrm{s}$ (рис. $3, c$ ). Течение материала при увеличении скорости деформации с величины 180 до 4561/s происходит под большим углом к направлению слоев.

На рис. 4 представлена структура АБС-пластика при температуре $\left(50^{\circ} \mathrm{C}\right)$ после испытаний с различными параметрами. При нагружении при повышенной до $50^{\circ} \mathrm{C}$ температуре также наблюдается слоистость материала при всех испытанных скоростях нагружения (рис. $4, b, d, g, h$ ).

Трещины располагаются вдоль слоев по их границе. Трещина зарождается и распространяется вдоль мест скопления включений второй фазы - бутадиенстирольного каучука как при скорости $4561 / \mathrm{s}$ (рис. 4, $a$ ), так и при скорости 987 1/s (рис. 4,e). Параболическая область в образцах со скоростями деформации 456 и $9871 / \mathrm{s}$ довольно хорошо выражена, как и область повышенной шероховатости (рис. $4, c, d, g, f$ ). Течение материала при обоих режимах происходит примерно под одним и тем же углом к направлению слоев.

Структура АБС-пластика при температуре $\left(100^{\circ} \mathrm{C}\right)$ после испытаний с различными скоростями представлена на рис. 5. При росте температуры испытаний до $1000 \mathrm{C}$ слоистость материала становится менее заметной - происходит гомогенизация пластика при всех испытанных режимах.

Трещины располагаются под углом к слоям при скорости 9871/s (рис. 5,i). Трещина зарождается и распространяется вдоль мест скопления включений второй фазы - бутадиенстирольного каучука при всех скоростях нагружения (рис. $5, a, i$ ). Параболическая область во всех образцах выражена слабо, как и область повышенной шероховатости, зато появляется зеркальная область (рис. $5, h, i$ ) при повышенных скоростях деформации 987 и 1745 1/s. Течение материала в образце, испытанном при малой скорости деформации $1801 / \mathrm{s}$, происходит примерно под углом $45^{\circ}$ к направлению слоев (рис. $5, a$ ), то есть по плоскостям максимальных касательных напряжений. В образце с большей скоростью деформации $9871 / \mathrm{s}$ - вдоль слоев (рис. 5,e), а в образце с максимальной скоростью деформации 1745 1/s носит сдвиговый характер (рис. 5,i) и происходит по скоплениям второй фазы.

\section{5. Заключение}

Показано, что температурно-скоростная зависимость хорошо описывается в рамках структурно временного подхода (1)-(3) не только в металлах, но и в полимерах, на примере АБС-пластика. Предложено построение единой теоретической кривой зависимости прочности АБСпластика от скорости деформации на основе структурновременного подхода.

Показано с помощью микроструктурных исследований, что трещина зарождается и распространяется вдоль мест скопления включений второй фазы - бутадиенстирольного каучука при всех скоростях деформации. При минимальной скорости испытаний $1801 / \mathrm{s}$ более развита область повышенной шероховатости, а параболическая область - менее ярко выражена. При скоростях деформации 456 и 987 1/s довольно хорошо выражена область повышенной шероховатости, как и параболическая область, что говорит о значительном поглощении энергии при распространении трещины. При повышенных скоростях деформации $9871 / \mathrm{s}$ и $17451 / \mathrm{s}$ и температуре $100^{\circ} \mathrm{C}$ появляется зеркальная область с медленным развитием трещины, что связано с гомогенизацией структуры и повышением пластичности материала. Течение материала при температуре $100^{\circ} \mathrm{C}$ при испытании с малой скоростью деформации $(180$ 1/s) происходит примерно под углом $45^{\circ}$ к направлению слоев, то есть по плоскостям максимальных касательных напряжений. С ростом скорости деформации до $9871 / \mathrm{s}$ - вдоль слоев, а в образце с максимальной испытанной скоростью деформации $17451 / \mathrm{s}$ носит сдвиговый характер и происходит по скоплениям второй фазы.

\section{Финансирование работы}

Работа выполнена при поддержке гранта РНФ 17-1101053. Экспериментальные исследования проведены с использованием оборудования ресурсного центра Научного парка СПбГУ „Исследование экстремальных состояний материалов и конструкций“.

\section{Конфликт интересов}

Авторы заявляют, что у них нет конфликта интересов.

\section{Список литературы}

[1] А.П. Александров, Ю.С. Лазуркин. ЖТФ 9, 14, 1250 (1939).

[2] А.М. Молодец. ФТТ 55, 11, 2090 (2013).

[3] T.L. Smith. Rubber Chem. Technology 51, 2, 225 (1978).

[4] O. Ishai. J. Appl. Polymer Sci. 11, 963 (1967).

[5] F. Povolo, E.B. Hermida. J. Appl. Polymer Sci. 58, 1, 55 (1995).

[6] C. Bauwens-Crowet. J. Mater. Sci. 8, 7, 968 (1973).

[7] А.Д. Евстифеев, А.А. Груздков, Ю.В. Петров. ЖТФ 83, 7 , 59 (2013).

[8] Ю.В. Петров, Е.В. Ситникова. ЖТФ 75, 8, 71 (2005).

[9] Y.V. Petrov, A.A. Utkin. Mater Sci. 25, 2, 153 (1989).

[10] Y.V. Petrov. AN USSR 321, 66 (1991).

[11] А.Д. Евстифеев, Г.А. Волков, А.А. Чеврычкина, Ю.В. Петров. ЖТФ 4, 567 (2019).

[12] Fracture processes in polymeric solids / Ed. B. Rousen. International Publishers, N.Y.-London-Sydney (1970). $523 \mathrm{p}$.

[13] С.А. Атрошенко, С.И. Кривошеев, А.Ю. Петров. ЖТФ 72 , 2, 52 (2002).

Редактор Т.Н. Василевская 